\title{
Seismic Retrofitting and Health Monitoring of School Buildings of Cyprus
}

\author{
C.Z. Chrysostomou ${ }^{1, *}$, N. Kyriakides ${ }^{1}$, A.J. Kappos ${ }^{2,3}$, L. Kouris ${ }^{3}$, E. Georgiou ${ }^{4}$ and M. Millis ${ }^{5}$ \\ ${ }^{I}$ Department of Civil Engineering and Geomatics, Cyprus University of Technology, PO Box 50329, 3603 Limassol, \\ Cyprus; ${ }^{2}$ Department of Civil Engineering, City University, London, UK; ${ }^{3}$ Department of Civil Engineering, Aristotle \\ University of Thessaloniki, Greece; ${ }^{4}$ Technical Services of the Ministry of Education and Culture of Cyprus; \\ ${ }^{5}$ SignalGeneriX, Cyprus
}

\begin{abstract}
The vulnerability of existing buildings to seismic forces and their retrofitting is an international problem. The majority of structures in seismic-prone areas worldwide are structures that have been designed either without the consideration of seismic forces, or with previous codes of practice specifying lower levels of seismic forces. In Cyprus, after the three earthquakes that occurred in 1995, 1996, and 1999, the Cyprus State, acting in a pioneering way internationally, has decided the seismic retrofitting of all school buildings, taking into account the sensitivity of the society towards these structures, which house the future generation of the society. In this paper the overall assessment methodology is presented, along with details of the over 10 year ongoing retrofitting program of the school buildings of Cyprus, with emphasis on the description of the program and the development of a wireless monitoring system. In addition, mathematical models of selected school buildings are presented and comparison is made with in-situ measurement.
\end{abstract}

Keywords: Seismic retrofitting, schools, health monitoring, existing structures.

\section{INTRODUCTION}

Cyprus, being located on the boundary of two tectonic plates, the Eurasian and the African ones, has high seismicity. The boundary between the two plates is located in the sea on the south-west of Cyprus and is the source of a large number of earthquakes. Historical reports and archeological findings show that Cyprus was affected by strong earthquakes that in many occasions have destroyed its cities. Based on historical data there were 16 destructive earthquakes between 26 B.C. and 1900 A.C. Instrumental data have started being collected after 1896, when seismological stations started operating in neighboring counties. In the period from 1896 to 2004, more than 400 earthquakes, with their epicenters in Cyprus and the surrounding regions, were felt on the Island. From these, 14 caused damage, and some caused fatalities. The most destructive earthquakes in this period were those of 1941, 1953, 1995, 1996 and 1999. The study of the historical and recent earthquakes shows that there is an irregular seismic activity, with active seismic periods being followed by inactive ones. During the period from 1995 to 1999 , an increase in the seismic activity was observed with strong earthquakes of magnitude ranging from 5.6 to 6.5 on the Richter scale being recorded.

Despite the recorded history of destructive earthquakes, the first seismic design measures in Cyprus were imposed after 1986 and the first seismic design code was introduced on a voluntary basis in 1992 and was made compulsory through a law in 1994. On January $1^{\text {st }} 2012$, all previous standards were withdrawn and were replaced by the

*Address correspondence to this author at the Department of Civil Engineering and Geomatics, Cyprus University of Technology, PO Box 50329, 3603 Limassol, Cyprus; Tel: +357 2500 2616; Fax: + 3572500 2769: Email: c.chrysostomou@cut.ac.cy
Eurocodes, including Eurocode 8 for the design of seismic resistant structures. Therefore, the majority of structures have been designed without any seismic provisions, which increases their vulnerability to seismic loads. Schools, which are a subset of the building inventory, belong to a very sensitive category of buildings. The Cyprus State, acting in a pioneering way internationally, has decided the seismic retrofitting of all school buildings, taking into account the sensitivity of the society towards these structures, which house the future generation of the society. Any loss of life due to their seismic vulnerability will have unbearable consequences.

In this retrofitting program the schools have either been retrofitted, refurbished (and in most cases a combination of the two), or demolished. The structural systems of the existing schools in Cyprus are either reinforced concrete, loadbearing masonry, or a dual system. The total number of school buildings in Cyprus is 660. Of these 26 were demolished and replaced by new ones at a cost of about 31 million Euros and 280 were retrofitted at a cost of 140 million Euros. The rest were designed after the enforcement of the seismic codes and thus do not require any intervention. As of today about $90 \%$ of the school buildings of Cyprus are seismic resistant.

The school-building population has suffered various levels of damage from earthquakes that took place during their life-time. The physical damage due to time-effects and in many cases the lack of maintenance, deteriorated their loadbearing capacity. In addition, many schools were constructed before the introduction of seismic codes or designed with previous seismic codes and therefore they were not able to withstand the currently specified seismic loads. It was therefore recognized that many schools needed seismic retrofitting. 
The effectiveness of this program is evaluated in an ongoing research project funded by the Cyprus Government and the European Regional Development Fund. This is done through a pilot application in which the cost-benefit method is used, adapted to local economic parameters, along with nonlinear structural analysis for the development of vulnerability curves, which will represent the condition of the structure both before and after strengthening, so as to make a first assessment of the school retrofitting project. In addition, an innovative wireless system of recording and analyzing signals is developed, which allows the in-situ recording of the dynamic characteristics of the structures in an effortless and affordable way, which will be the reference point for any future measurements. Finally, a life-cycle cost analysis methodology is developed that will allow the selection of the optimum level of future strengthening taking into account both technical as well as economic parameters, such as the up-to-date investment for the retrofitting of schools, the remaining life, as well as the maintenance cost of structural and non-structural elements (i.e. electrical and mechanical installations etc.).

In this paper the details of the over 10 year ongoing retrofitting program of the school buildings of Cyprus, with emphasis on the description of the program and the development of the wireless monitoring system are described. In addition, mathematical models of selected school buildings are presented and comparison is made with in-situ measurement.

In the first part of the paper, the guideline that was used to assess the safety of school buildings is presented. Then, the school inventory is described along with the details of the retrofitting parameters, such as methodologies used, cost etc. This is followed by the description of the wireless system that was developed for the in situ recordings. The last part of the paper includes the description of the analytical simulation of the selected buildings and the results of the modal analysis along with a comparison with the recordings.

\section{GUIDELINE FOR THE ASSESSMENT OF THE SAFETY OF SCHOOL BUILDINGS}

Following the decision for the retrofitting of the school buildings, which was a repercussion of the 1999 earthquakes of Turkey, Athens and Cyprus, a Technical Committee was formed to develop a guideline for the "Assessment of the Safety of School Buildings" [1]. The Technical Committee consisted of two members of the Scientific and Technical Chamber of Cyprus and two members of the Technical Services of the Ministry of Education and Culture of Cyprus. At the time that this program started there were no retrofitting codes available either in Cyprus or abroad. There where though guidelines, such as FEMA 273 [2], which outlined concepts and methodologies to be used for retrofitting. These concepts and methodologies formed the basis for the development of the guideline for the retrofitting of the school buildings, the main provisions of which are outlined below.

The methodology followed was to establish the existing condition of the structure, select a safety level against which the structure was checked and make a decision for retrofitting measures to be taken, considering at the same time economic and social factors. In case that retrofitting was needed, strengthening measures were taken until the safety level was satisfied.

The establishment of the existing condition of the structure included data about the soil properties, environmental conditions that may affect the structure, as well as the seismic zone in which it was located. In addition, it was required to collect all the available architectural and detailing drawings, including design calculations, the determination of the location and sizes of structural and nonstructural elements and identification of the structural system, possible changes that took place during the lifetime of the structures and finally, the technical characteristics of the building materials and condition of structural members with visual inspection and selective in-situ, as well as laboratory testing.

The safety level selected was that of "Life Safety". In this level, conforming buildings may suffer extensive damage both in structural and non-structural elements. They may need repairs in order to become operational and the repair may be economically infeasible. The thread to human life in buildings satisfying the requirements of this safety level is low.

This safety level was associated with ground accelerations that were specified in the Cyprus Seismic Code [3]. Taking into consideration the definition of the seismic action in this code, the seismic action was specified for a design life of 10,20 and 50 years with a probability of exceedance of $10 \%$. For buildings retrofitted in full according to the Cyprus Seismic Code, a Peak Ground Acceleration (PGA) for 50 years was used, while for those that are expected to be replaced in 20 or 10 years, a PGA for 20 or 10 years were used, respectively. These estimates that are expressed in the form of PGA $\left(\mathrm{A}_{\max }\right)$ and are defined for the seismic zones of the Cyprus Seismic Code are shown in (Table 1). The parameter of soil type was not included in the determination of $A_{\max }$.

Table 1. Peak Ground Accelerations Per Seismic Zone (Cyprus Seismic Code [3])

\begin{tabular}{|c|c|c|c|}
\hline \multirow{3}{*}{ Seismic Zone } & \multicolumn{3}{|c|}{ Peak Ground Acceleration, $\mathrm{A}_{\max }$} \\
& \multicolumn{3}{|c|}{ (g) } \\
\cline { 2 - 4 } & $\begin{array}{c}\text { Design Life } \\
50 \text { years }\end{array}$ & $\begin{array}{c}\text { Design Life } \\
20 \text { years }\end{array}$ & $\begin{array}{c}\text { Design Life } \\
10 \text { years }\end{array}$ \\
\hline \hline $1,2,3$ & 0.075 & 0.075 & 0.075 \\
4 & 0.100 & 0.075 & 0.075 \\
5 & 0.150 & 0.100 & 0.075 \\
\hline
\end{tabular}

The design acceleration was specified using the design spectrum defined in the Cyprus Seismic code [3], which is described by the following two equations and shown in (Fig. 1):

$$
\begin{aligned}
& S_{d}=\frac{I \cdot A_{\max } \cdot 2.5}{K} \text { for } T \leq T_{1} \\
& S_{d}=\frac{I \cdot A_{\max } \cdot S \cdot 2.5}{K}\left(\frac{T}{T_{1}}\right) \text { for } T>T_{1}
\end{aligned}
$$


where $S_{d}$ is the design spectral acceleration, $I$ is the importance factor, $A_{\max }$ is the peak ground acceleration defined in (Table 1) for various design lives of the structures, $S$ is the soil coefficient, $K$ is the behaviour factor of the structural system, $T$ is the fundamental period of the structure and $T_{l}$ is the corner period between the acceleration and the velocity regions of the design spectrum. It is specified in the technical guideline that the importance factor should be taken equal to 1.5 , while the behavior factor should be equal to 2.0 and 1.5 for infilled reinforced concrete frames and load-bearing masonry structures, respectively. The latter two values can be changed if adequate justification is presented.

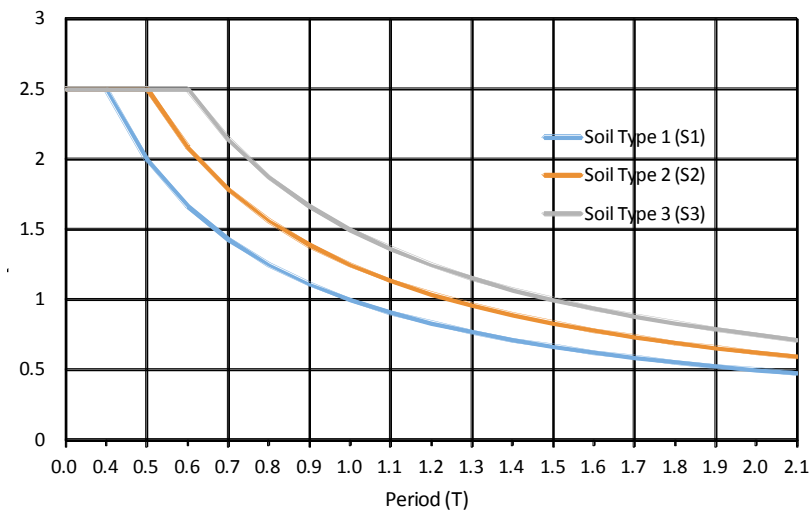

Fig. (1). Cyprus Seismic Code design spectrum for three soil types.

The above apply to all types of structures while the acceptance criteria are specified for each of the two types of materials used for the construction of schools, namely, reinforced concrete and masonry. For the reinforced concrete it is specified that the mean concrete cylinder strength should be larger than $10 \mathrm{MPa}$ and that none of the specimens should have strength less than $8 \mathrm{MPa}$. The number of specimens is specified as one specimen per two classrooms with a minimum number of 6 specimens per floor, for each independent part of every wing, for every building or group of buildings. If the above limits are not satisfied then further specimens should be taken. Regarding reinforcement it is required that the diameter loss is restricted to $15 \%$ and that the yield strength should be no less than $220 \mathrm{MPa}$. In case that there is severe rusting it is required that the reinforcement is replaced. It is also required that the contribution of infill walls is taken into account with a conservative estimate of the compressive strength of hollow bricks bonded with mortar to be taken as $1.8 \mathrm{MPa}$ and the corresponding shear strength to be $0.9 \mathrm{MPa}$. Chemical analyses are also required to establish the level of carbonation, as well as the presence of chlorites and/or sulphates.

Acceptance criteria are also specified for member forces and interstory drifts. The former are satisfied if checked against the provisions of the Cyprus Reinforced Concrete Code, now replaced by Eurocode 2, and the latter by checking against $2 \%$ for recoverable drifts, or $1 \%$ for unrecoverable ones. At least two load combinations are used shown below:

$$
\begin{aligned}
& 1.35 G+1.5 Q \\
& 1.00 G+0.5 Q+E(G+0.5 Q)
\end{aligned}
$$

where $G$ is the permanent load and $Q$ is the live load specified equal to $3 \mathrm{kN} / \mathrm{m}^{2}$ and $E$ is the earthquake load.

Of utmost importance are the economic criteria that are specified, which state that if the cost of retrofitting exceeds one third of the replacement cost of the specific structure, then the decision for retrofitting is taken by a technical committee that consists of the designer, two governmental engineers, a representative of the Director General of the Ministry and a member of the School Board. The purpose of this committee is to decide whether to proceed with the retrofitting or decide for the school demolition and its replacement.

Both the equivalent-static and response spectrum methods are allowed to be used for the analysis of the structures. In both cases, infill walls should be modeled either with two equivalent diagonal bars, or surface finite elements. Nonlinear methods are also allowed to be used. Several methods are suggested to remove any deficiencies that increase the vulnerability of buildings such as removal of eccentricities, soft stories, short column, disconnected stairwells, beam supported columns etc., through the introduction of new structural elements, such as frames or structural walls. These measures can increase the stiffness as well as the strength of the structure, or both. The reduction of the mass, whenever possible, is also suggested, as well as local interventions on an element by element basis. Some suggested methodologies are the use of reinforced concrete jackets, $\mathrm{R} / \mathrm{C}$ walls or carbon fibres.

Similar provisions are given for load-bearing masonry structures. Due to the fact that the majority of these structures are single-story ones, special conditions are provided that whenever satisfied the structure is deemed to satisfy the acceptance criteria. These conditions are related to the length of solid walls per direction of the structure, the absence of cracks on the walls and the integrity and thickness of the load-bearing walls. Because of the difference of construction relative to the reinforced concrete ones, and the sensitive nature of such structures (which are considered as part of the cultural heritage), the methods suggested for retrofitting them are different than the ones described above for reinforced concrete structures. The use of injections and/or prestressing tendons, the construction of a ring beam, as well as the pointing of the joints, are the main methods proposed in the guideline. In addition, special care is taken for the introduction of diaphragmatic action, so as the seismic forces are shared by all the load-bearing walls.

\section{COLLECTION OF DATA FOR THE RETROFIT- TING OF THE SCHOOLS IN CYPRUS}

In order to assess the effectiveness of the program, a data collection was performed, in order to obtain the details of the building inventory and the methods that were used for the retrofitting of schools. This was a very laborious task since to obtain these data one had to look into the records kept in paper form by the Ministry of Education and Culture. It was impossible to check every single folder; therefore the data presented here cover the majority of the schools but not all of them for the period up to the end of April 2011.

Since vulnerability and cost/benefit analysis will be used for the assessment, a number of parameters were defined and 
collected during this operation, which will facilitate the assessment. These are: 1) the number of buildings each school consists off, since they may consist of different structural systems and may have different ages, 2) the year of construction, including the starting and finishing date of the construction, which is related to the design code used and consequently the design accelerations, 3) the structural system of each school, 4) the height of each building, 5) the type of intervention, which may include seismic retrofitting, strengthening, or refurbishment (such as changing of tiles, painting, upgrading of electrical and mechanical installations, etc.), or even expansions to cover new needs of the school, 6) method of intervention based on the guideline presented in the previous section, which includes jackets, structural walls, carbon-fibres, steel elements, or mixed methods for R/C buildings, and construction of ring beams, replacement of masonry elements, strengthening or replacement of roofs for masonry structures, 7) the acceleration that was specified for the design/retrofitting of the structures, 8) the service life that was used as described in Table 1,9) the remaining life of the structure, 10) the material properties of the structure before any intervention, 11) the results of chemical analyses, if any, 12) the retrofitting cost that covers only the cost of the intervention on the structural system, which in this case it was very difficult to be identified since it was mixed with the cost of other simultaneous interventions in the school building, and 13) the replacement cost, which is defined as the cost for building a new school.

\subsection{Analysis of the Data}

As of early 2012, 280 schools have been retrofitted with 20 being in the process of being retrofitted, while another 26 were demolished and replaced. The remaining of the schools were designed after the enforcement of seismic codes. As it was mentioned before, it was not possible to have access to all the folders kept by the Ministry of Education and Culture, therefore, the data presented below refer to the recorded data for 117 schools all over Cyprus. Even for these schools, the 13 parameters mentioned in Section 3 were not always possible to be recorded, since they were missing from the records, therefore some of the graphs presented below correspond to a subset of these schools. For each graph the sample size is indicated for easy reference.

As it is shown in (Fig. 2), 68\% of the school buildings in Cyprus are made of reinforced concrete, $22 \%$ is a dual system consisting of reinforced concrete and masonry, and $10 \%$ are made of masonry.

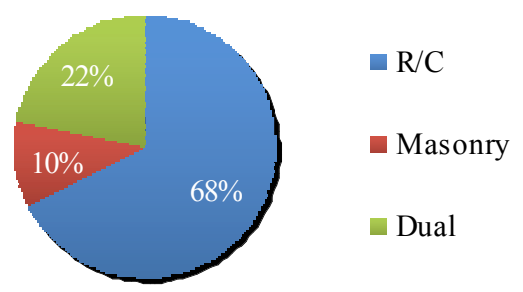

Fig. (2). Structural system of school buildings (sample: 105 schools).

Of these, $73 \%$ were built before 1986, $12 \%$ between 1986 and 1992, and 15\% after 1992 (Fig. 3). The signifi- cance of these dates is that before 1986 all structures in Cyprus, including schools, were designed for gravity loads only, without any provisions for earthquake loads. In 1986, the first guidelines for seismic design were introduced followed by the introduction of the $1^{\text {st }}$ Cyprus Seismic Code in 1992, which was made compulsory in 1994. It is therefore clear that only $15 \%$ of the schools were designed for seismic loads, while another $12 \%$ were designed using the guidelines. This made the need for upgrading the schools for seismic loading imperative.

In $50 \%$ of the buildings upgrading, strengthening and maintenance operations were undertaken (Fig. 4) while only for $8 \%$ it was required, in addition to the above, to make expansion of the school and upgrading of the electrical and mechanical installations.

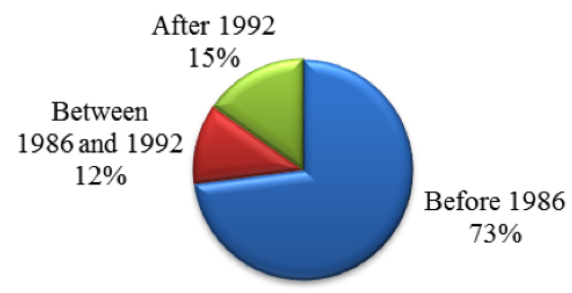

Fig. (3). Period of construction of school buildings (sample: 111 schools).
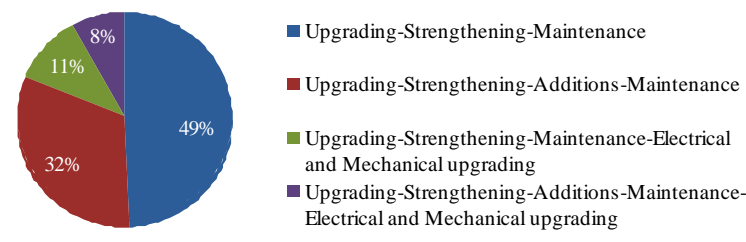

Fig. (4). Type of intervention in school buildings (sample: 111 schools).

Another very important parameter that had to be decided was the selection of the design life (Table 1), which had an effect on the acceleration for which the schools were going to be designed. As it is shown in (Fig. 5), 79\% of the schools were designed for a 20 year remaining life, $19 \%$ for a period of 50 years while only $2 \%$ for a period of 10 years. Hence, based on this graph, the majority of the school buildings will need to be re-assessed in about 10 to 20 years from now.

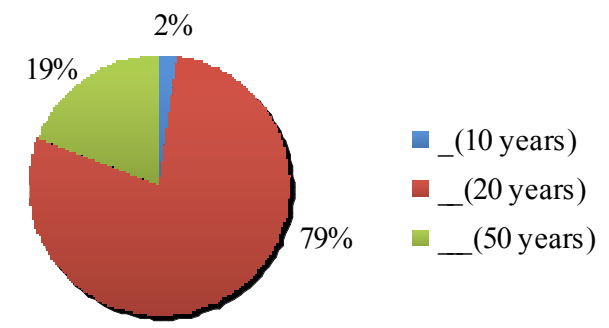

Fig. (5). Service-life of school buildings (sample: 47 schools).

The strengthening cost of school buildings is shown in (Fig. 6). Although special care was taken to include only the strengthening cost excluding maintenance or other costs, these numbers may include some of these costs. It can be 
observed from (Fig. 6) that the strengthening cost for $38.7 \%$ of the schools was up to 225,000 Euros and for $29.3 \%$ between 225,000 and 525,000 Euros. The mean value of the strengthening cost was 483.667 Euros. To get an idea of the level of the additional costs, it is noted that the Contract Value (total cost of construction) varied from 75,992 Euros to 2,120,711 Euros.

The replacement cost is shown in (Fig. 7) in which it is indicated that $65 \%$ of the schools have a replacement value of up to 500,000 Euros, with another $22 \%$ in the bracket of 500,000 and 1,000,000 Euros. This is a very important value, which was used to make the decision for strengthening or not as explained earlier.

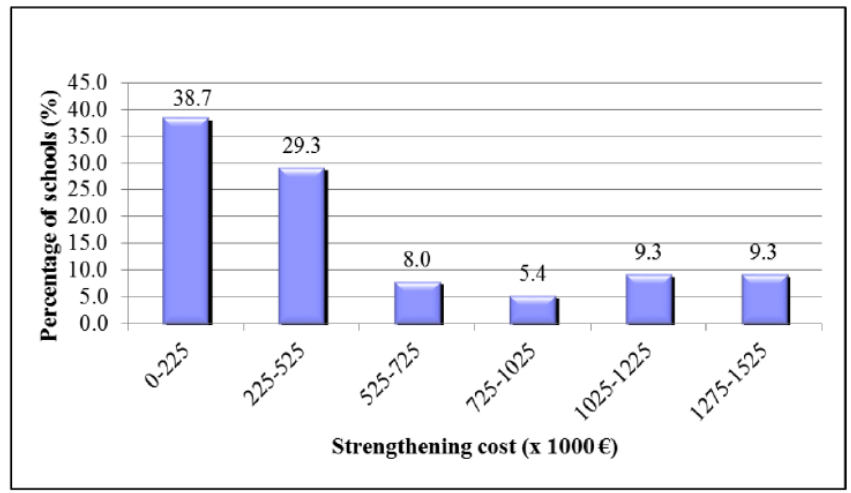

Fig. (6). Strengthening cost of school buildings (sample: 75 schools).

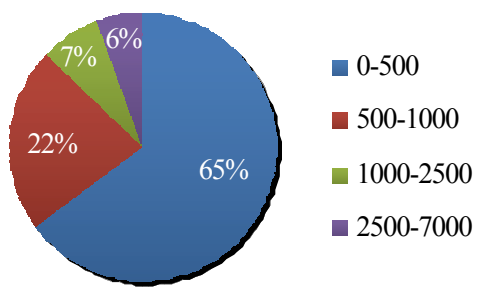

Fig. (7). Percentage of schools per replacement cost bracket (x $1000 €$ ) (sample: 109 schools).

The next five graphs illustrate the findings regarding the methods of strengthening used. (Fig. 8) shows that the majority of R/C jackets were used on columns (79\%), followed by jackets on beams (17\%) and the rest of the jackets concerned jacketing of external infill walls. When structural walls were used as a method of retrofitting (Fig. 9), in the majority of the cases $(80 \%)$ new ones were constructed while in $16 \%$ of the cases existing columns were converted into walls, and in only $4 \%$ of the cases external infill walls were partially replaced by $\mathrm{R} / \mathrm{C}$ walls.

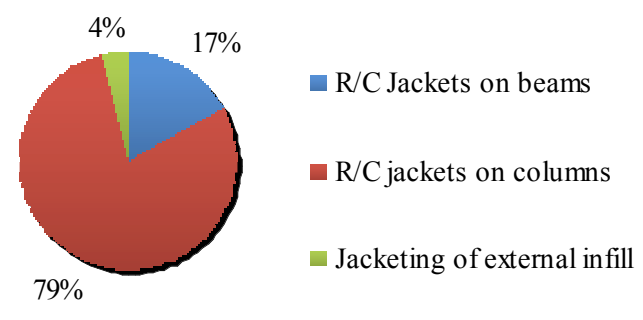

Fig. (8). Retrofitting with R/C jackets (sample: 53 schools).
For 11 schools in the sample there was a need for retrofitting the foundation (Fig. 10). In $37 \%$ of the cases a new foundation was required, while strengthening with additional reinforcement or with R/C jackets was required for $27 \%$ of the cases, respectively. For $9 \%$ of the cases the foundation was not according to the original drawings and it had to be altered so as to meet the design.

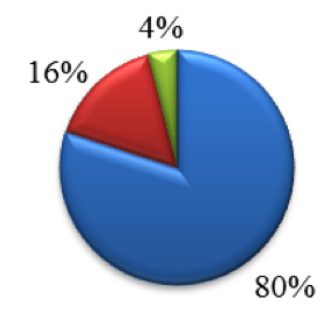

\section{Dew structural walls \\ घConversion of columns to walls \\ $\square$ Partial replacement of external infills with $\mathrm{R} / \mathrm{C}$ walls}

Fig. (9). Retrofitting with R/C structural walls (sample: 25 schools).

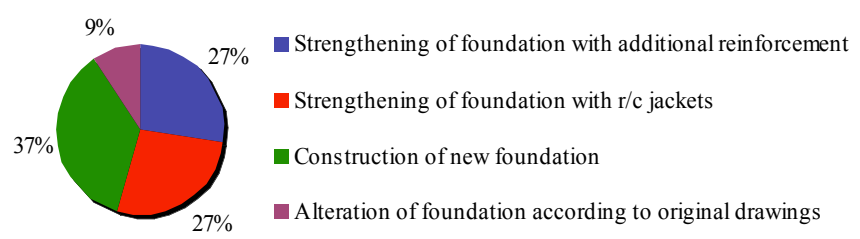

Fig. (10). Retrofitting of foundations (sample: 11 schools).

The methods used for the retrofitting of columns are shown in (Fig. 11). In $74 \%$ of the cases columns were strengthened using $\mathrm{R} / \mathrm{C}$ jacket, while in $14 \%$ of the cases FRPs were used. In the rest of the cases either the shear or the column reinforcement was increased. For beams (Fig. 12) in $31 \%$ of the cases $R / C$ jackets were used, while in $50 \%$ of the cases FRPs were used, either in the form of wraps $(7 \%)$ or in the form of strips (14\%) with the rest $29 \%$ not identified specifically.

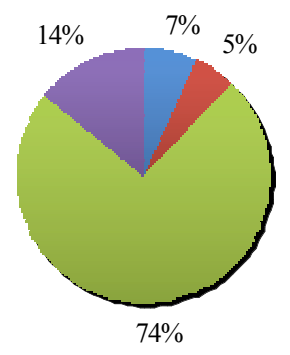

$$
\begin{aligned}
& \text { Increase of column reinforcement } \\
& \text { Increase of column shear reinforcement } \\
& \text { R/C jackets on columns } \\
& \text { - FRPs on columns }
\end{aligned}
$$

Fig. (11). Method for retrofitting columns (sample: 57 schools).

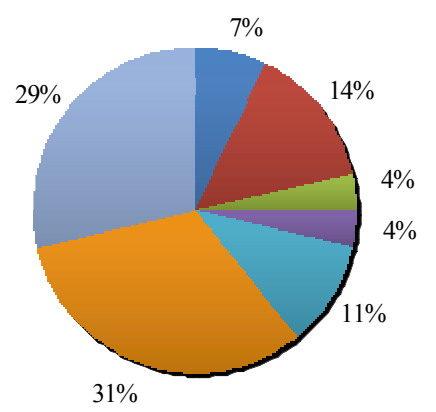

$$
\begin{aligned}
& \text { - Carbon fibre wraps on beams } \\
& \text { - Carbon fibre strips on beams } \\
& \text { - Increase of beam reinforcement } \\
& \text { - Increase of beam shear links } \\
& \text { - Increase of beam thickness } \\
& \text { - } \mathrm{R} / \mathrm{C} \text { jackets on beams } \\
& \text { - FRPs on beams }
\end{aligned}
$$

Fig. (12). Method for retrofitting beams (sample: 20 schools). 


\section{DESCRIPTION OF THE WIRELESS SYSTEM DE- VELOPED}

An innovative wireless system of recording and analyzing signals has been developed within this research project that will allow the in-situ recording of the dynamic characteristics of the structures in an effortless and affordable way, which will be the reference point for any future measurements. Any changes in their period of vibration compared to this benchmark will signify the need for a detailed investigation for locating the sources of any possible problem. This system can be also used for before and after the intervention measurements, to be able to establish the changes in the dynamic characteristics of a structure after the application of the selected retrofitting scheme.

The innovation of this wireless system lies in the fact that it can be used for recording signals from ambient excitations. This requires a 16 bit resolution of the recorded data which is very demanding for a wireless system. The system consists of two independent subsystems (Fig. 13): the first one on the left of the figure is the personal computer on which the developed graphical unit interface (GUI) is running, and the second one is the wireless sensors system, which consists of the data-processing unit Advantech ARK 1360, the receiver unit MC-USB 1608FS and the selected sensors. The received data are stored in a database which is located in the dataprocessing unit. The communication between the two subsystems is achieved through Wi-Fi that provides adequate bandwidth for efficient data transfer. The complete wirelessnode system developed by the partner of the project SignalGeneriX is shown in (Fig. 14).

The system can be extended in the future to record parameters such as carbonation and oxidation (when the accuracy and reliability of such sensors is improved) that will allow the application of corrective measures before the effects of these parameters become visible. It is the wish of the Technical Services of the Ministry of Education and culture to install such systems on as many schools as possible, so as to have the capability of remotely monitoring the structural behaviour of their structures and be able to take corrective measures in due time.

\section{SELECTION OF TYPICAL BUILDINGS}

Based on the database created from the data collection, two school buildings were selected to determine their vulnerability and assess the retrofitting methods used, which was the main scope of this study. In order to cover the whole spectrum of school buildings in Cyprus certain criteria were set for the selection. Initially the construction material, which influences considerably the vulnerability of a building, was set as a criterion. Based on the fact that nearly $70 \%$ of the Cyprus school-buildings are $\mathrm{R} / \mathrm{C}$ whereas a considerable $30 \%$ are masonry, it was decided to examine one building from each material category. Secondly, the year of construction was examined as a criterion influencing the vulnerability. It was concluded that the majority of $\mathrm{R} / \mathrm{C}$ schoolbuildings were constructed prior to the enforcement of the Minimum Aseismic measures in 1986 and thus were designed with no seismic loading provisions, which increases considerably their vulnerability. Therefore, the selected R/C school was designed in early 1980 s with no seismic provisions. Further to that, a 2 story RC building was selected since more than $50 \%$ of the school buildings of that period fall into this height category. The final criterion was related to the retrofitting method used for the upgrading of the building. The selected building was retrofitted using $\mathrm{R} / \mathrm{C}$ jackets, which was the most popular retrofitting method used in the program.

The $\mathrm{R} / \mathrm{C}$ building was approximately $200 \mathrm{~m}^{2}$ in plan $(20 \mathrm{~m} \times 10 \mathrm{~m})$ with $\mathrm{R} / \mathrm{C}$ frames at $3 \mathrm{~m}$ spacing providing the resistance in the short direction. In the long direction 2 lines of columns are present connected only through the slab. A skylight extending to a height of approximately $500 \mathrm{~mm}$ below the slab was left open to enhance the lighting of the building. During the retrofitting of the building steel truss members were introduced to strengthen the opening and provide frame action in the long direction as well. In the short direction the frame beams have dimensions $300 \mathrm{mmX} 700 \mathrm{~mm}$ and they were not strengthened. The back view of the selected R/C building is shown in (Fig. 15) and a plan view in (Fig. 16). As far as the columns are concerned, they are placed in two lines, one in each side of the building in the long direction. Their initial dimensions of all the columns were $300 \mathrm{~mm} \times 300 \mathrm{~mm}$. More than half of them were increased in area $(500 \mathrm{mmx} 500 \mathrm{~mm})$ using $\mathrm{R} / \mathrm{C}$ jackets for retrofitting purposes.

In the case of the masonry building, the selection was less complicated since the majority of them consist of onestory with load bearing stone walls and timber pitched roof. As far as their retrofitting is concerned, in most cases an RC beam was added to the perimeter of the building at the roof level. This method is referred to as "shenaz" in the literature and is intended to provide confinement to the building and connection between the walls.
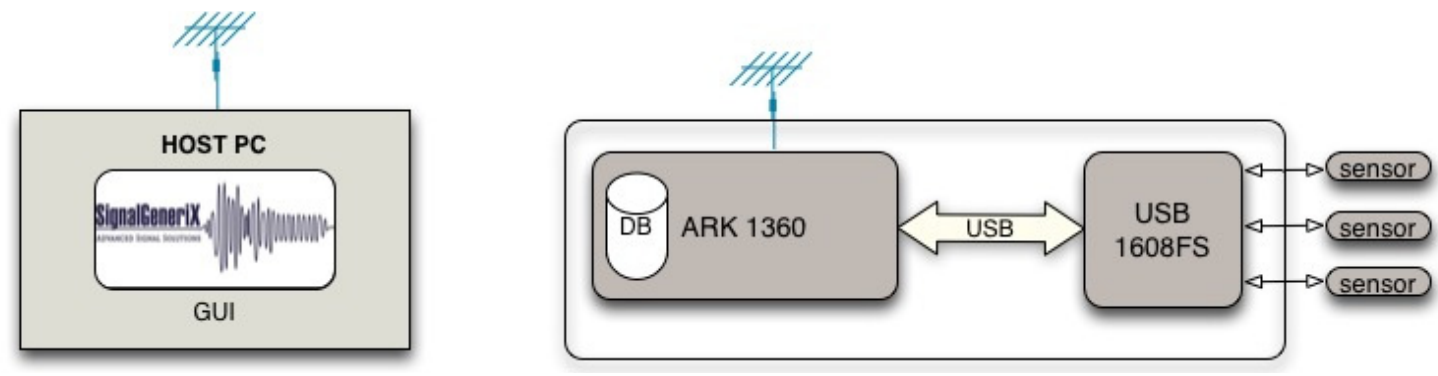

Fig. (13). Wireless system. 


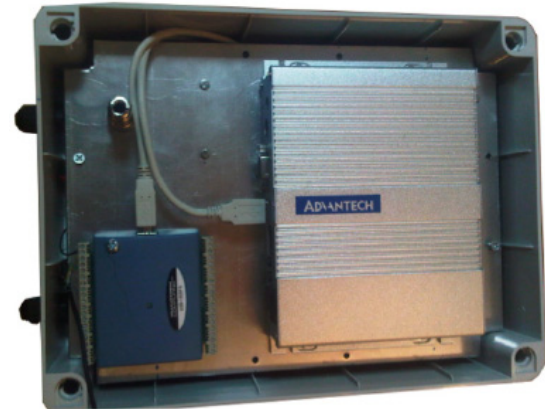

Fig. (14). The complete wireless-node system.

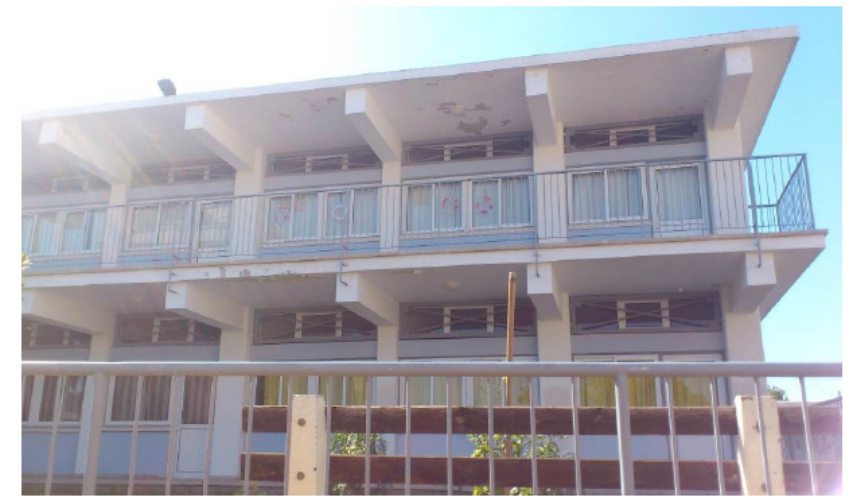

Fig. (15). Back view of the selected strengthened R/C building.

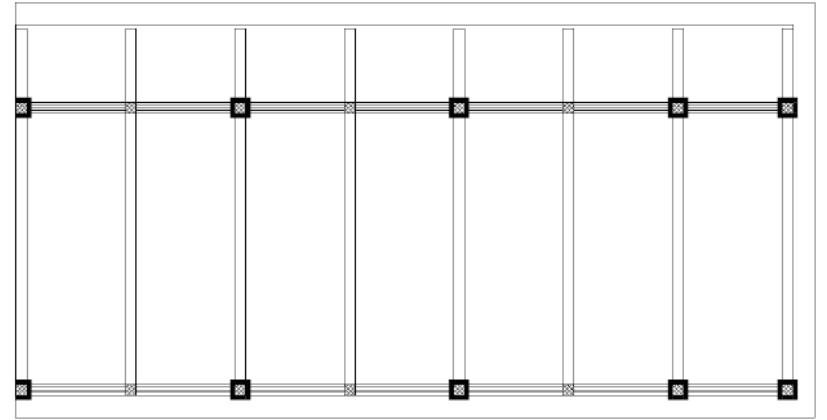

Fig. (16). Plan view of the selected strengthened R/C building.

The front view of the masonry building is given in (Fig. 17) and a plan view is shown in (Fig. 18). It is of $\Pi-$ shape in plan and consists of thick load bearing walls (approximately $600 \mathrm{~mm}$ thick). The compressive capacity of the walls was approximated at about $4.27 \mathrm{MPa}$ based on the type of the stone and test results from similar buildings.

The two selected buildings will be used to examine at a later stage their vulnerability through analytical probabilistic studies. Initially, mathematical models of the buildings were developed in order to determine their dynamic characteristics through elastic modal analysis. The analytical dynamic characteristics are compared to the ones obtained from in-situ measurements, so as to update the mathematical models that will form the basis for non-linear analyses that will be used for the determination of their vulnerability. In the remaining part of this paper the models for the two buildings are first described along with the results of the modal analysis, and then the results of the in-situ recordings are presented along with their comparison to the analytical ones.

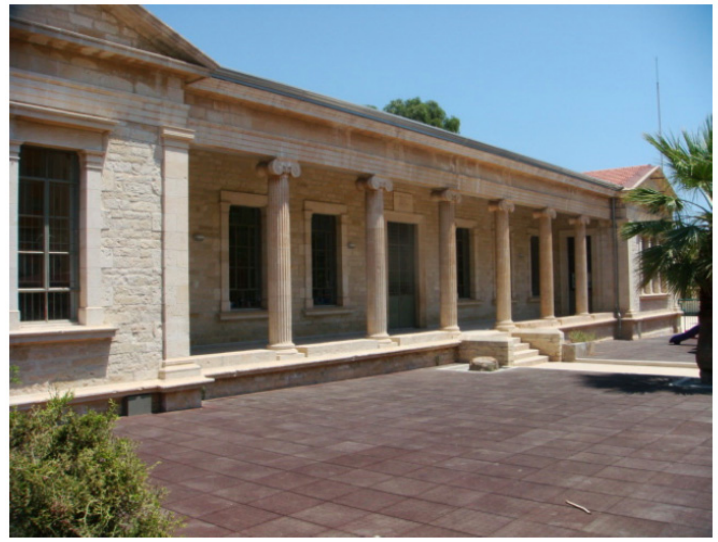

Fig. (17). Front view of the selected Masonry building.

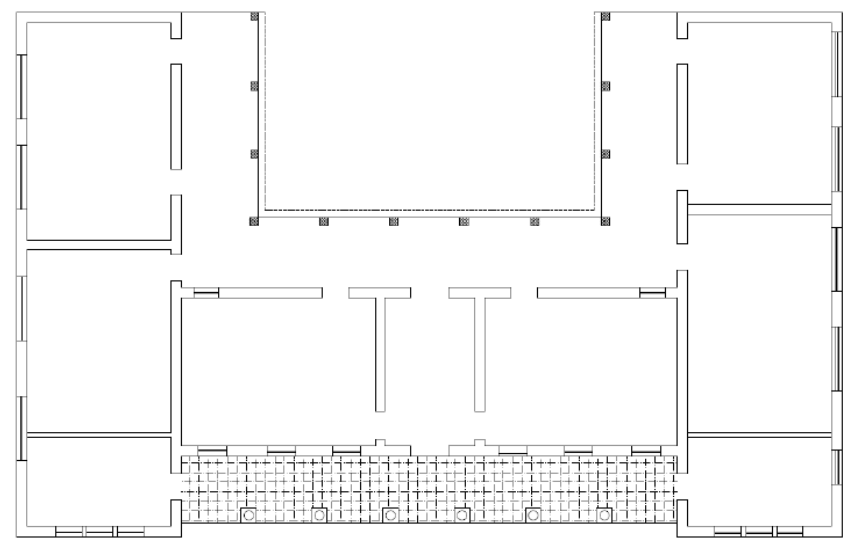

Fig. (18). Plan view of the selected Masonry building.

\section{MODAL ANALYSIS RESULTS}

In order to assess the vulnerability of the school buildings and the efficiency of the retrofitting method used, sophisticated analysis needs to be conducted to capture their nonlinear behavior under seismic loading. Such an analysis relies heavily on the analytical simulation of the actual building. Therefore it was decided to produce analytical models primarily in ANSYS [4], and compare the results of the modal analysis to in-situ recordings of ambient and/or forced vibrations. The comparison is repeated using a more general analysis software, SAP2000 [5], which is more readily available to practicing engineers. Both simulation models consisted of line elements (columns and beams) and shell elements to simulate the slabs.

Initially the $\mathrm{R} / \mathrm{C}$ building was modelled using ANSYS [4]. Masses were distributed on slabs and a reduced stiffness $50 \%$ of uncracked was assumed for columns and beams to account for the effect of cracking. Fig. (19) shows the analytically obtained $1^{\text {st }}$ mode of vibration that corresponds to a period of $1.31 \mathrm{~Hz}$, whereas (Fig. 20) shows the mode shape of the $2^{\text {nd }}$ mode of vibration $(1.45 \mathrm{~Hz})$. The $1^{\text {st }}$ mode shape corresponds to vibration of the building along its longitudinal direction whereas the $2^{\text {nd }}$ mode is along the lateral (short) direction.

The same analysis was repeated on the simulation frame created on SAP2000 [5], which can also be used for nonlinear analysis and provides simpler modeling capabilities. 

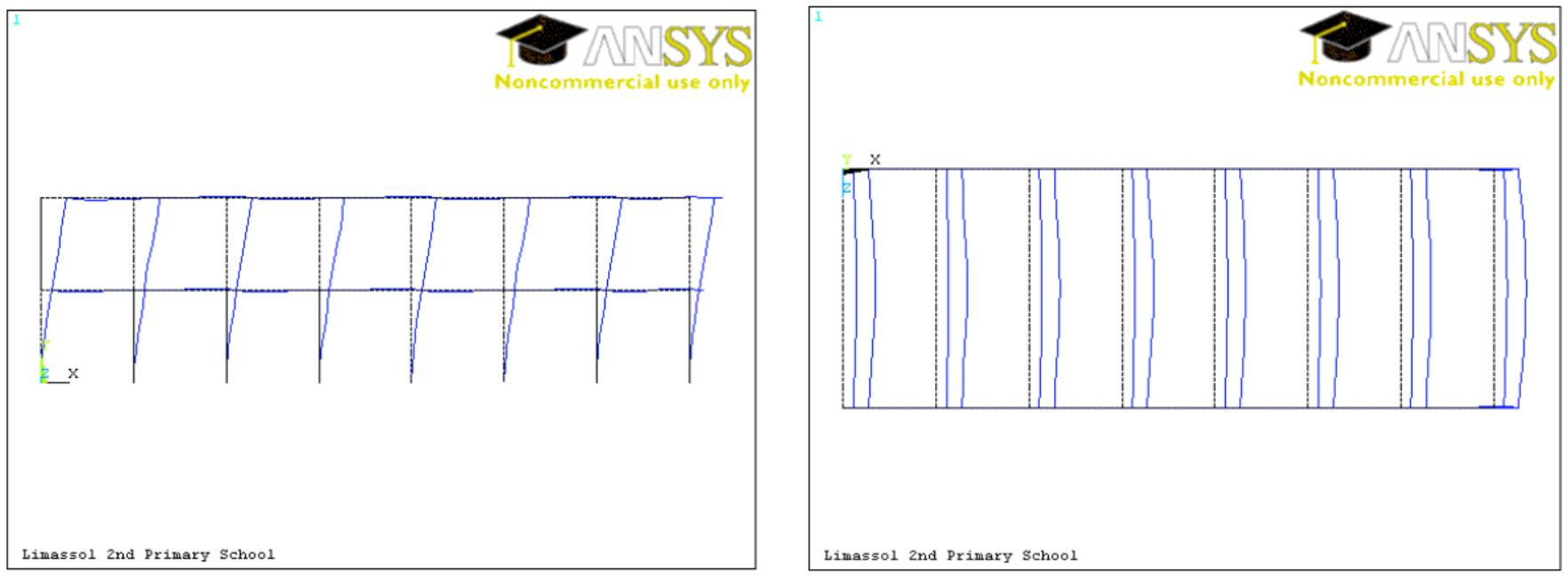

Fig. (19). Side view and plan of the $1^{\text {st }}$ mode of vibration of R/C building using ANSYS $(1.31 \mathrm{~Hz})$.
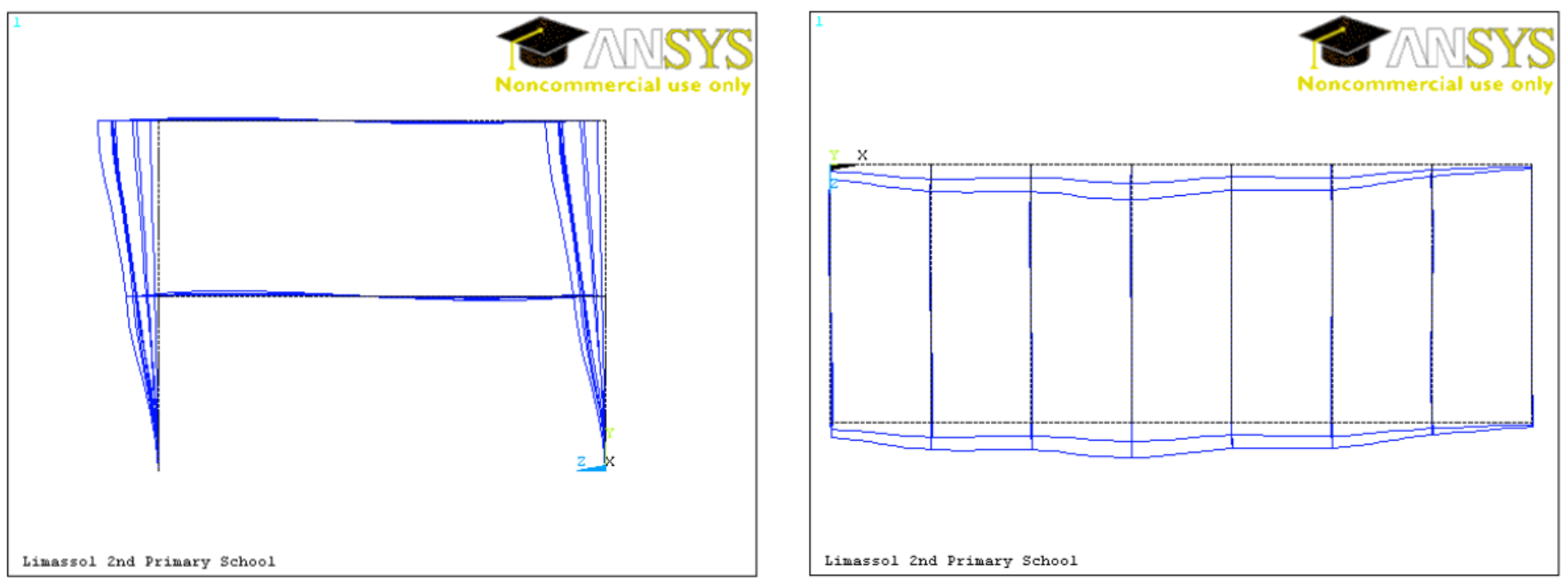

Fig. (20). Side view and plan of the $2^{\text {nd }}$ mode of vibration of R/C building using ANSYS $(1.45 \mathrm{~Hz})$.

The results of the modal analysis for the $1^{\text {st }}$ and $2^{\text {nd }}$ modes of vibration are shown in (Figs. 21 and 22). The comparison of the corresponding results from both simulation frames clearly shows excellent correlation.

The modal analysis on the Masonry building was conducted using shell elements with low modulus of elasticity $(\mathrm{E}=2.85 \mathrm{GPa})$ and various foundation conditions. Fixed and hinged conditions were analysed; in the pinned case there is no allowance for vertical settlement. Moreover, more realistic support conditions were explored, i.e. soil B and D (according to Eurocode 8), wherein vertical compliance $(\mathrm{Kz}$ springs) was also taken into account. The latter were modeled using vertical linear Winkler-type springs. The results of modal analysis are shown in (Table 2).

Fig. (23) shows the $1^{\text {st }}$ and $2^{\text {nd }}$ mode shapes for the masonry building, corresponding to periods of vibration $0.26 \mathrm{~s}$ and $0.23 \mathrm{~s}$, respectively, for the fixed support conditions.

\section{IN-SITU RECORDINGS}

This part of the paper includes the results from the in-situ recording on the 2 selected buildings using an accelerometer network. The recordings were conducted using both a wired and wireless (see paragraph 4) accelerometer networks.

In the case of the masonry building, the accelerometers were placed on the lintel over the windows as shown in (Fig. 24), in order to monitor the vibration of the stone walls next to the selected windows. These walls were found in the analysis to vibrate at a higher extend compared to the rest of the walls at the side of the building. Ambient vibration recordings were conducted the results of which are shown in (Figs. 25 and 26). As can be seen in (Fig. 26), the recorded $1^{\text {st }}$ and $2^{\text {nd }}$ periods of vibration of the building are $0.26 \mathrm{~s}$ and $0.23 \mathrm{~s}$, respectively.

In the case of the $\mathrm{R} / \mathrm{C}$ building, 3 accelerometers were used for the wired network (Fig. 27) and 1 for the wireless (Fig. 28). One of the wired accelerometers was placed near a column of the $1^{\text {st }}$ floor whereas the remaining 2 were placed on the corner frame, one at each side of the building in the short direction (front and back).

The analysis of the ambient vibration recordings was conducted on DASYLab [6]. Fig. (29) shows the recorded frequencies of the $1^{\text {st }}(1.28 \mathrm{~Hz}$ or $0.78 \mathrm{~s})$ and $2^{\text {nd }}(1.50 \mathrm{~Hz}$ or $0.67 \mathrm{~s}$ ) modes of vibration of the building. 


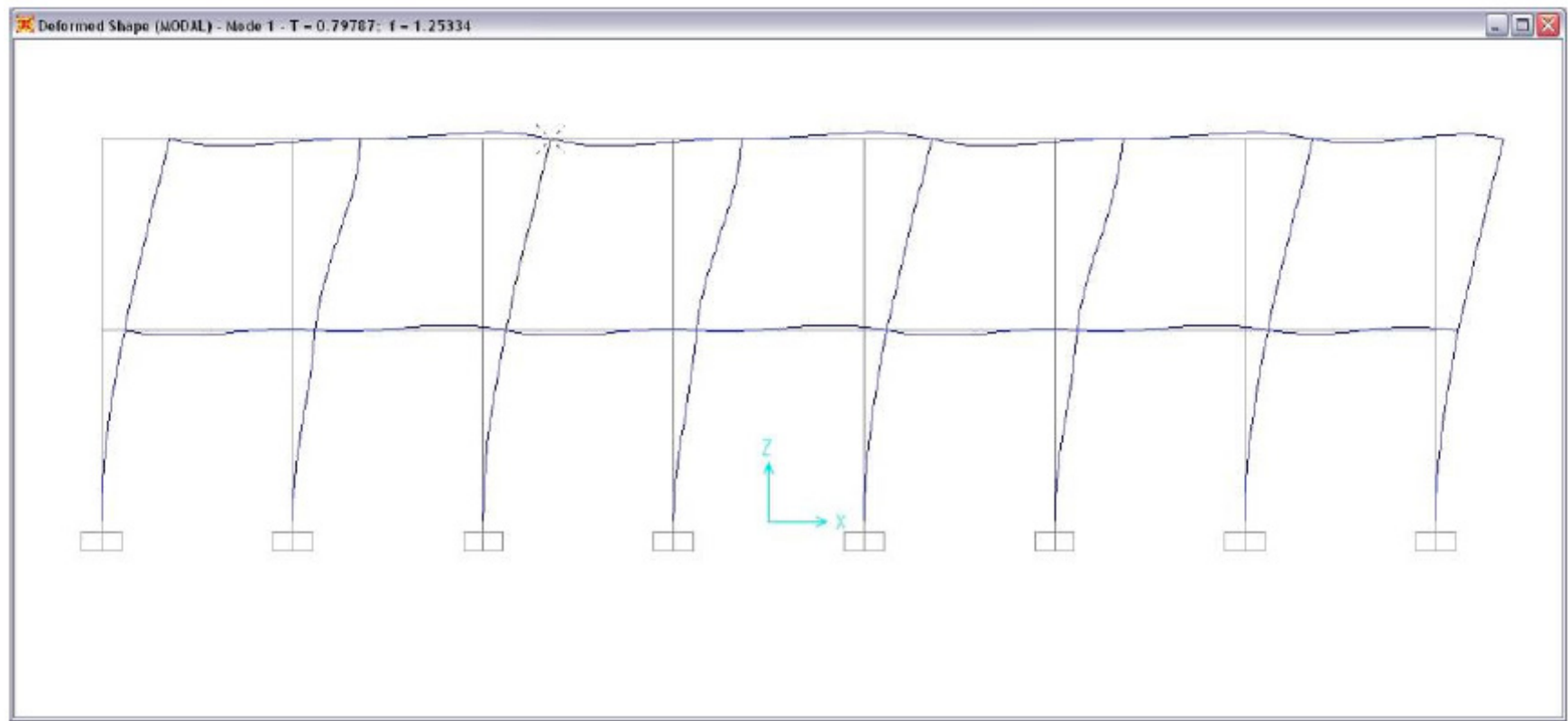

Fig. (21). View of the $1^{\text {st }}$ mode of vibration of R/C building using SAP2000 (1.25Hz).

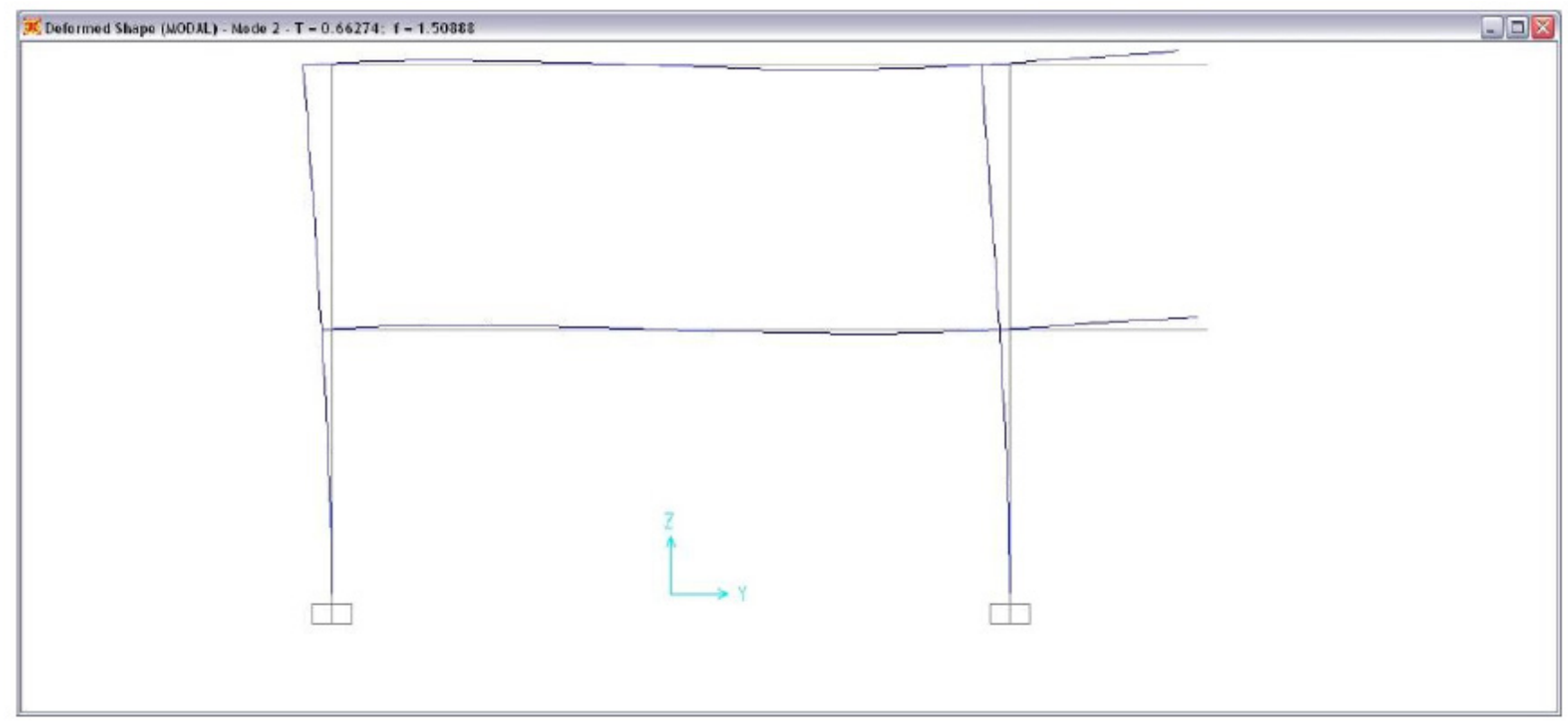

Fig. (22). View of the $2^{\text {nd }}$ mode of vibration of R/C building using SAP2000 $(1.50 \mathrm{~Hz})$.

Table 2. Periods of Vibration for the Masonry Building

\begin{tabular}{|c|c|c|c|c|}
\hline \multirow{2}{*}{ Mode Shape } & \multicolumn{4}{|c|}{ Stone Modulus of Elasticity of Masonry matrix $E=2.85 \mathrm{GPa}$} \\
\hline & \multicolumn{4}{|c|}{ Period of vibration (s) } \\
\hline 1 & 0.259 & 0.342 & 0.343 & 0.348 \\
\hline 2 & 0.230 & 0.288 & 0.288 & 0.293 \\
\hline 4 & 0.162 & 0.186 & 0.187 & 0.195 \\
\hline
\end{tabular}


Mode 1

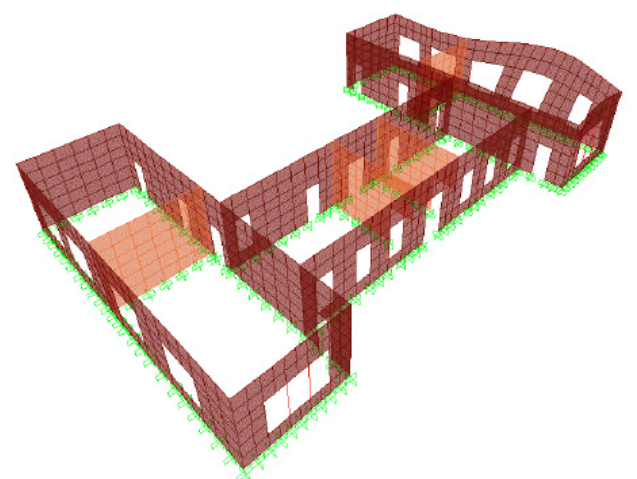

Mode 2

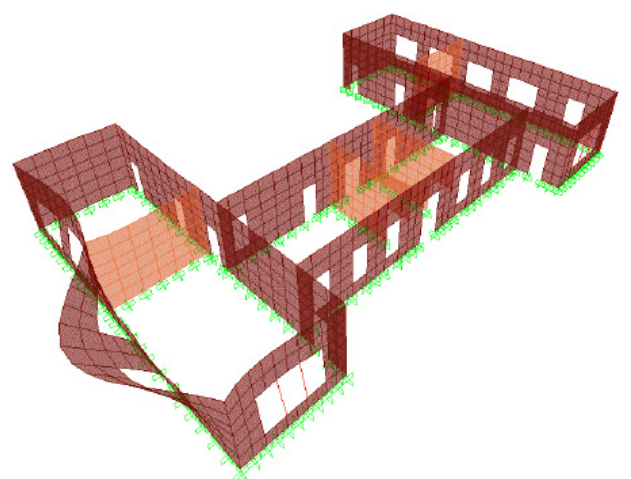

Fig. (23). $1^{\text {st }}$ and $2^{\text {nd }}$ mode shapes for the Masonry building for fixed support conditions.

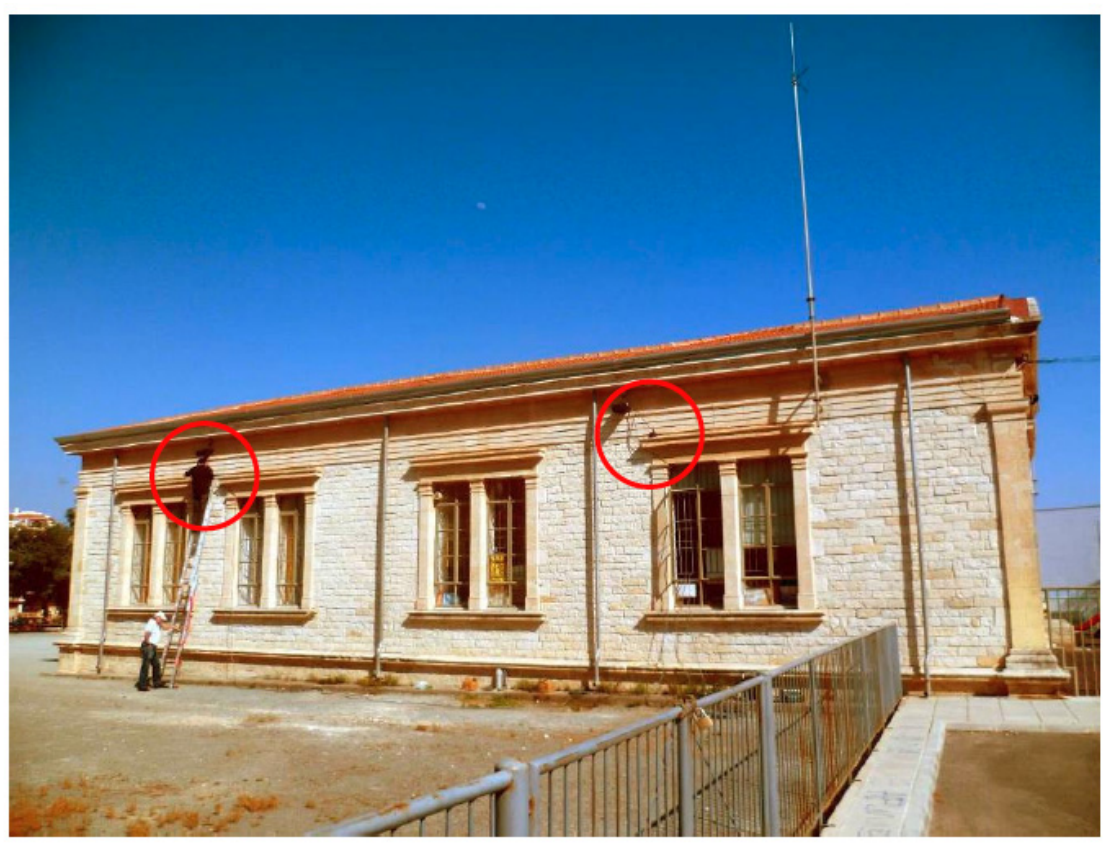

Fig. (24). Position of the 2 accelerometers at one side of the building.

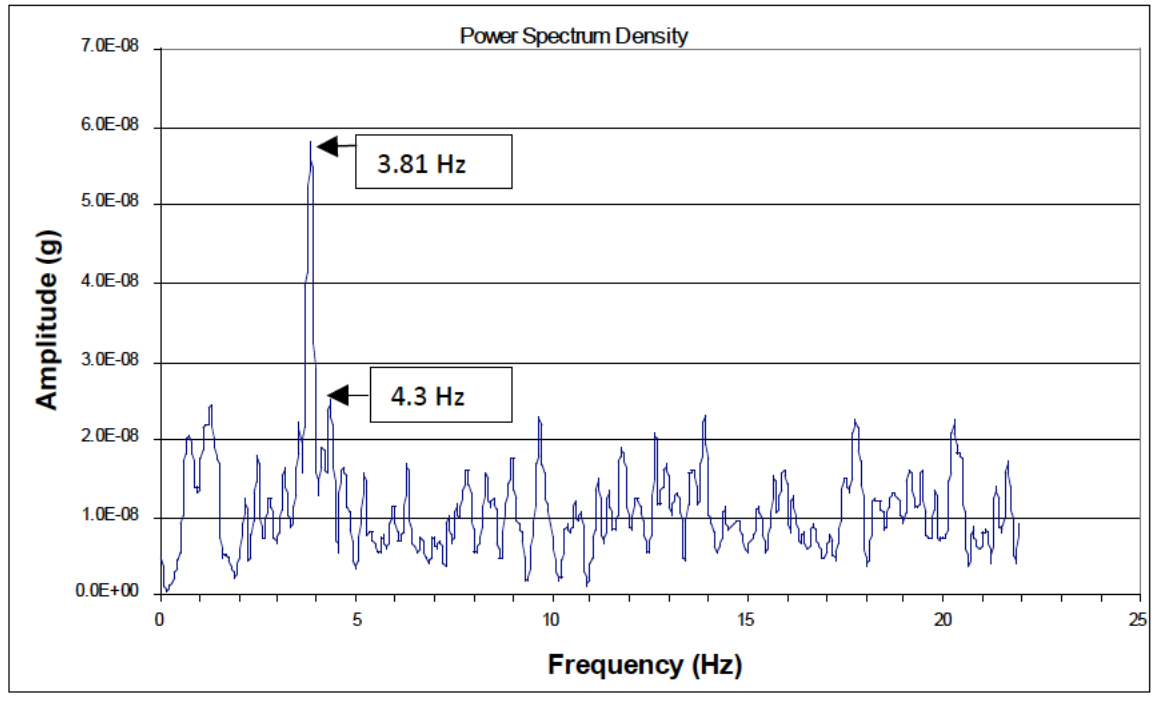

Fig. (25). Power Spectrum Density in frequency terms. 


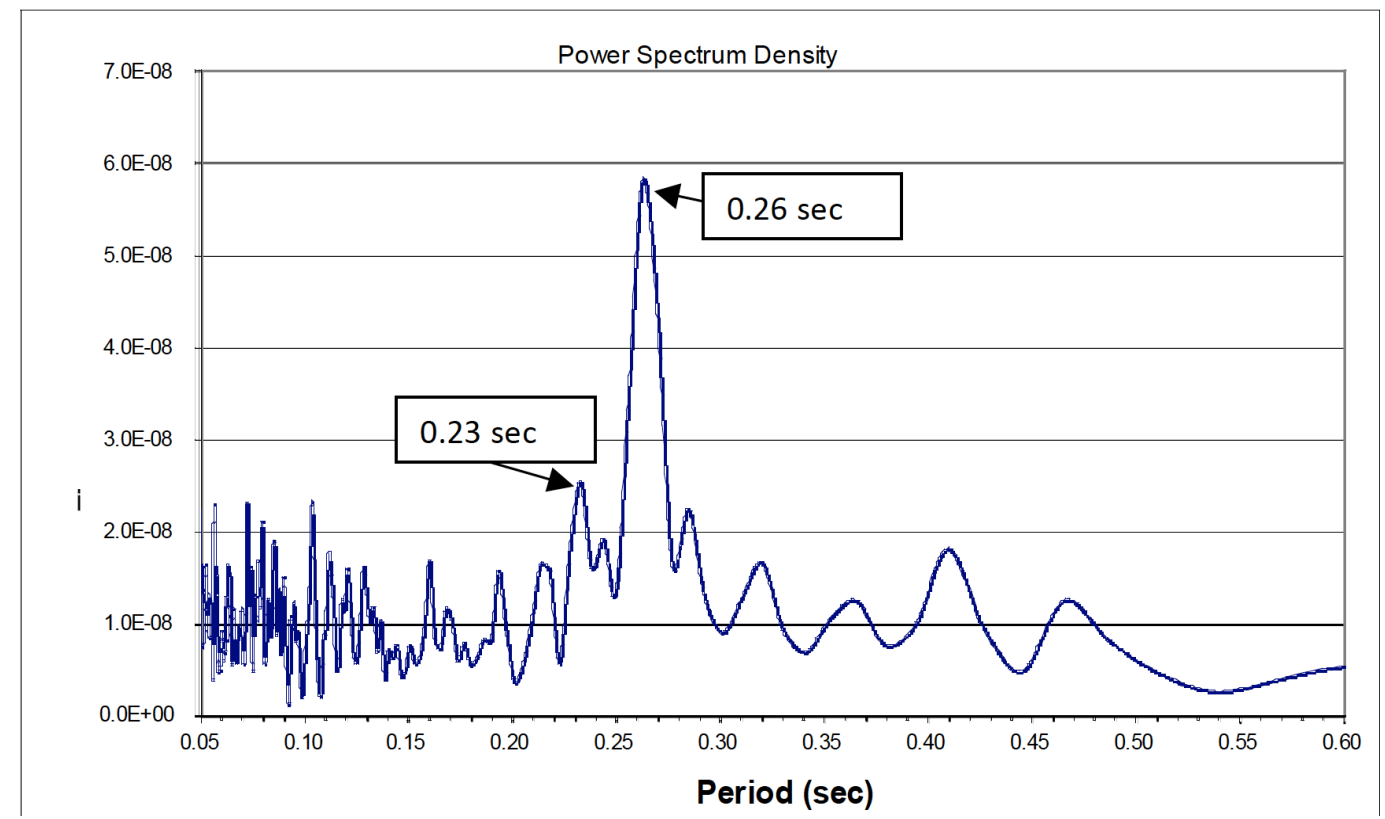

Fig. (26). Power Spectrum Density in period terms.

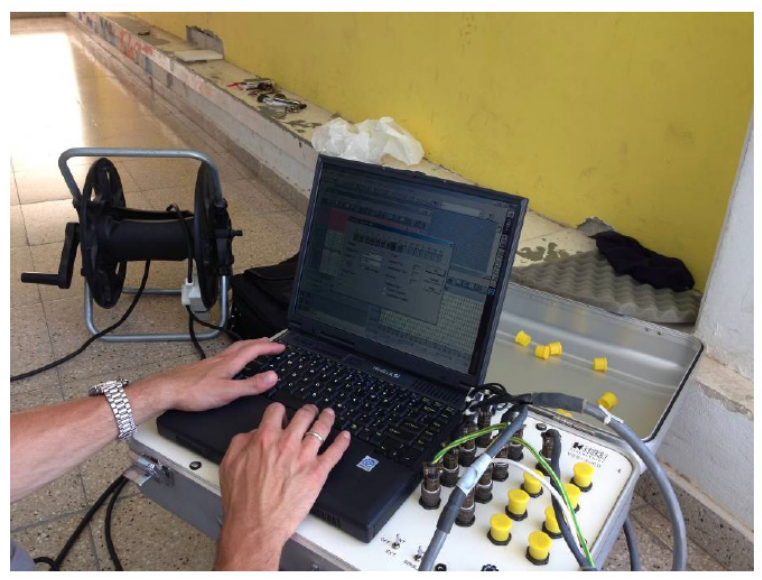

Fig. (27). Wired network recording unit.

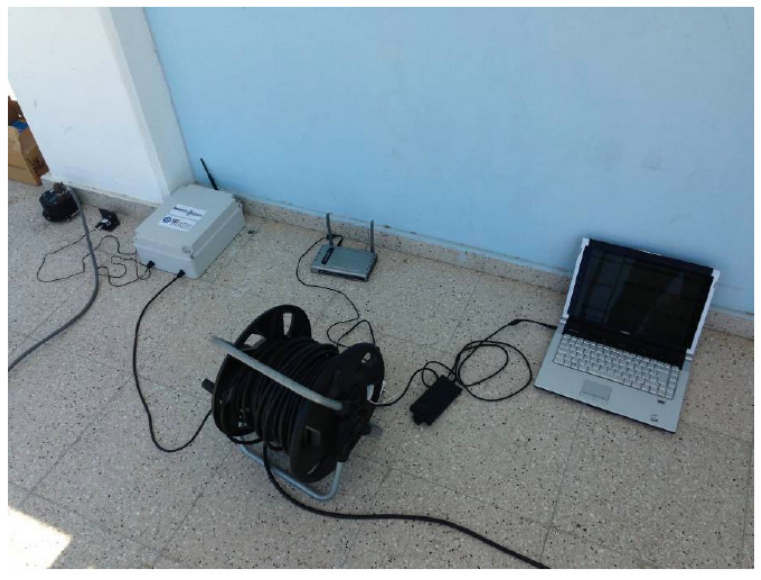

Fig. (28). Wireless network recording unit.

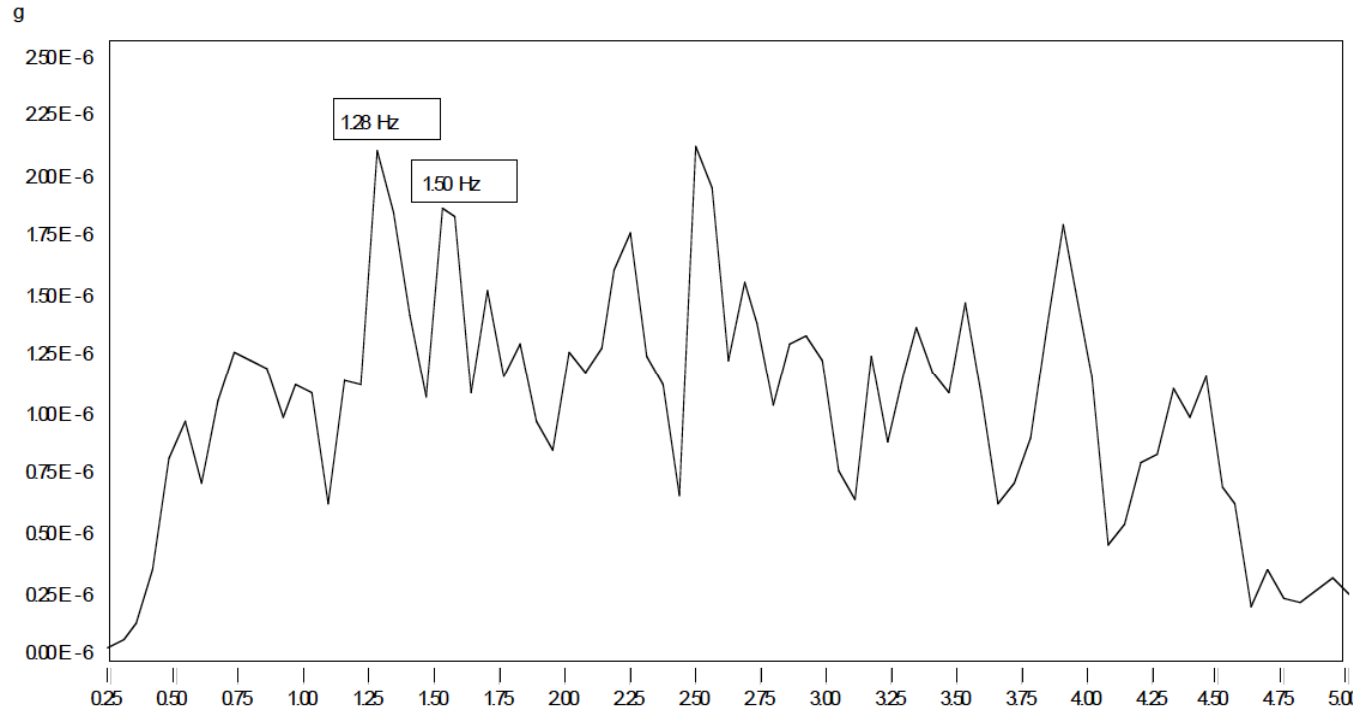

Fig. (29). Fourier Spectrum of the recordings on the R/C building. 


\section{COMPARISON OF RECORDINGS TO SIMULA- TION RESULTS}

From (Fig. 23) it is observed that for stiff foundation conditions, the first two analytical mode shapes have periods $0.26 \mathrm{~s}$ and $0.23 \mathrm{~s}$, respectively, which are equal to the ones resulted from the in-situ measurements shown in (Fig. 26). Therefore the assumption made for the modulus of elasticity (taken as $667 \mathrm{f}_{\mathrm{cm}}$, where $\mathrm{f}_{\mathrm{cm}}$ the compressive strength of masonry) and the stiff foundation conditions are verified. It can be noted that although the accelerometers were placed on the left-hand-side wall, it was possible to capture the period of vibration of the $1^{\text {st }}$ mode that has the largest amplitude on the right-hand-side wall of the building. This is also reported in measurements from other masonry monuments [8-10], in which cases the periods of vibration were captured by accelerometers irrespective of their position. It is expected though that a period of vibration of a certain mode can be more easily obtained if the accelerometer is placed exactly at the position where the maximum amplitude of the mode-shape takes place.

In the case of the $\mathrm{R} / \mathrm{C}$ building, Table 3 shows a comparison of the modal analysis results of the 2 simulation frames with the in-situ recorded frequencies and periods. It is obvious that the dynamic characteristics of the analytical models are very close to the ones of the actual building. This provides confidence in the accuracy of the analytical models in the elastic range which can therefore be used as the basis for the development of nonlinear models that are required for vulnerability analysis.

Table 3. Comparison of the Analytical and Recorded Periods of Vibration of the $R / C$ Building

\begin{tabular}{|c|c|c|c|c|}
\hline \multirow{2}{*}{} & \multicolumn{2}{|c|}{$\mathbf{1}^{\text {st }}$ mode shape } & \multicolumn{2}{c|}{$\mathbf{2}^{\text {nd }}$ mode shape } \\
\cline { 2 - 5 } & $\mathbf{H z}$ & Seconds & $\mathbf{H z}$ & Seconds \\
\hline \hline ANSYS & 1.31 & 0.76 & 1.45 & 0.69 \\
\hline SAP2000 & 1.25 & 0.80 & 1.50 & 0.67 \\
\hline IN-SITU RECORDING & 1.28 & 0.78 & 1.50 & 0.67 \\
\hline
\end{tabular}

In order to strengthen the verification of the analytical models for the $\mathrm{R} / \mathrm{C}$ building, the mode shapes corresponding to the recorded periods of vibration were computed using ARTeMIS [7]. The $1^{\text {st }}$ mode obtained from the in-situ measurements is given in (Fig. 30). The building is clearly vibrating along its long direction which verifies the plan-view of the mode shape in (Fig. 19). The same applies for the comparison of the $2^{\text {nd }}$ mode shape obtained from the recordings (Fig. 31), when compared to the plan-view of the mode shape in (Fig. 20).

\section{SUMMARY}

In this paper the pioneering retrofitting program of school buildings of Cyprus that took place over the last decade has been presented. Details about the retrofitting guideline, as well as the methods for retrofitting used are presented. The development of an innovative wireless system of recording and analyzing signals that has been developed within this research project is described, that will allow the in-situ recording of the dynamic characteristics of the structures in an effortless and affordable way, which will be the reference point for any future measurements. Any changes in their period of vibration compared to this benchmark will signify the need for a detailed investigation for locating the sources of any possible problem. This system can be also used for before and after the intervention measurements, to be able to establish the changes in the dynamic characteristics of a structure after the application of the selected retrofitting scheme. The use of this system is demonstrated through the determination of the dynamic characteristics of two representative school buildings, a reinforced concrete and an unreinforced masonry one, by analyzing the results of in-situ measurements and comparing to the ones obtained from analytical models. These models have formed the basis for nonlinear analyses that have been used for the determination of the vulnerably of school building through a benefit-cost as well as a more sophisticated life-cycle analysis, which will be described in a future publication.

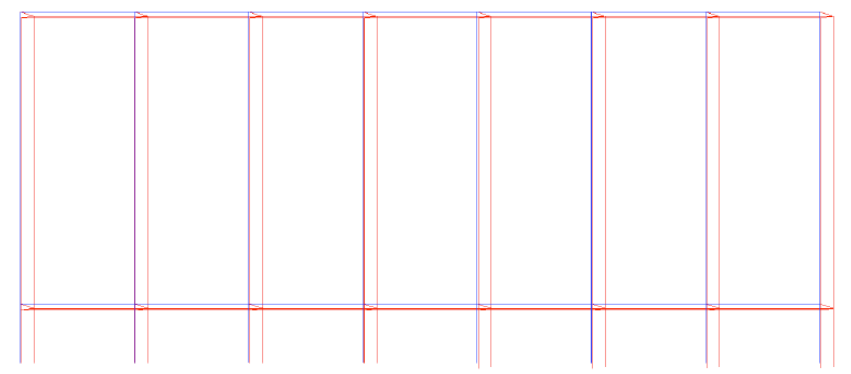

Fig. (30). Plan view of $1^{\text {st }}$ mode shape along the long direction of the building as computed using ARTeMIS (red line indicates the mode shape).

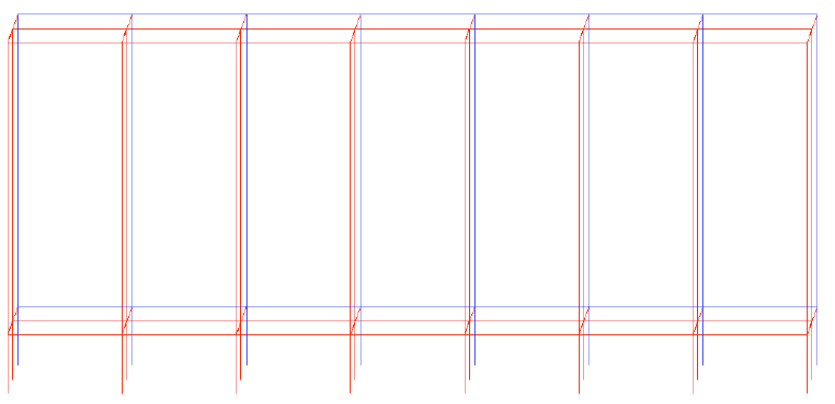

Fig. (31). Plan view of $2^{\text {nd }}$ mode shape along the lateral direction of the building as computed using ARTeMIS (red line indicates the mode shape).

\section{CONFLICT OF INTEREST}

The author(s) confirm that this article content has no conflicts of interest.

\section{ACKNOWLEDGEMENT}

This project AЕІФОРІA/A $\Sigma T I / 0609(\mathrm{BIE}) / 06$ is funded under DESMI 2009-10 of the Research Promotion Foundation of Cyprus and by the Cyprus Government and the European Regional Development Fund. The authors would like to acknowledge also the contribution of Ms. Elpida Georgiou in the collection of data for the school retrofitting program. 


\section{REFERENCES}

[1] C. Z. Chrysostomou, Th. Demetriou, E. Georgiou, and A. Karydas, Safety assessment of school buildings: Goals and targets of retrofitting: Strengthening methodologies and safety upgrading, Technical Manual, Ministry of Education and Culture, Nicosia, Cyprus, 2000.

[2] FEMA 273. NEHERP, Guidelines for the seismic rehabilitation of buildings, Federal emergency Management Agency report no.273, Applied Technology Council, Washington, USA, 1997.

[3] Cyprus Seismic Code, Cyprus Association of Civil Engineers and Architects, Nicosia, Cyprus 1994

[4] $\quad$ ANSYS $^{\circledR}$ Academic Research, Release 13.0

[5] SAP2000 ${ }^{\circledR}$, Computers and Structures, Release 14.0
[6] DASYLab ${ }^{\circledR}$, National Instruments, Release 9.0

[7] $\quad$ ARTeMIS $^{\circledR}$, Structural Vibration Solutions A/S, Release 5.2

[8] C. Z. Chrysostomou, T. Demetriou, M. Pittas, and A. Stassis, "Retrofit of a church with linear viscous dampers", Journal of Structural Control and Health Monitoring, vol. 12, no. 2, pp. 197212.

[9] C. Z. Chrysostomou, Th. Demetriou, and A. Stassis. "System identification of an ancient aqueduct", Journal of Smart Structures and Systems, vol. 4, no. 2, pp. 183-194, 2008.

[10] R. A. Votsis, N. Kyriakides, C. Z. Chrysostomou, E. A. Tantele, and T. Demetriou, "Ambient vibration testing of two masonry monuments in Cyprus", Soil Dynamics and Earthquake Engineering, vol. 43, pp. 58-68, 2012.

(C) Chrysostomou et al.; Licensee Bentham Open.

This is an open access article licensed under the terms of the Creative Commons Attribution Non-Commercial License (http://creativecommons.org/licenses/by-nc/3.0/) which permits unrestricted, non-commercial use, distribution and reproduction in any medium, provided the work is properly cited. 